\title{
Effects of Anti-C5a Antibodies on the Adult Respiratory Distress Syndrome in Septic Primates
}

\author{
John H. Stevens, Peter O’Hanley, Jeffrey M. Shapiro, Frederick G. Mihm, Paul S. Satoh,“ \\ John A. Collins, and Thomas A. Raffin \\ Departments of Medicine, Surgery and Anesthesiology, Stanford University School of Medicine, Stanford, \\ California 94305; and *Upjohn Diagnostics, Kalamazoo, Michigan 49001
}

\begin{abstract}
In vitro and in vivo studies have suggested that human complement component C5a plays a key role in neutrophil injury in the adult respiratory distress syndrome (ARDS). First, using leukocyte aggregometry, we demonstrated that the addition of a recently developed rabbit anti-human polyclonal antibody to C5a des arg to endotoxin-activated plasma prevented leukocyte aggregation in vitro. We then administered the anti-C5a des arg antibody to septic primates (Macaca fascicularis). Three groups of primates, control, septic, and anti-C5a antibody treated septic, were studied ( $n=4$ in each group). A 30-min infusion of Escherichia coli $\left(1 \times 10^{10} / \mathrm{kg}\right)$ resulted in severe sepsis and ARDS. Primates were killed $4 \mathrm{~h}$ after completion of the $\boldsymbol{E}$. coli infusion. Septic animals not treated with anti-C5a antibody had $75 \%$ mortality (3/4), decreased oxygenation, severe pulmonary edema, and profound hypotension. Septic primates treated with antiC5a antibodies did not die and did not develop decreased oxygenation $(P<\dot{0.05})$ or increased extravascular lung water $(P$ $<0.05)$. They also had a marked recovery in their mean arterial blood pressure $(P<0.05)$. This study demonstrates that treatment with rabbit anti-human C5a des arg antibodies attenuates ARDS and some of the systemic manifestations of sepsis in nonhuman primates.
\end{abstract}

\section{Introduction}

The adult respiratory distress syndrome (ARDS) ${ }^{1}$ is a common and often fatal complication of septic shock $(1,2)$. Several cellular and humoral factors have been implicated in the pathogenesis of ARDS, including neutrophils, platelets, fibrin, arachidonic acid metabolites, serotonin, histamine, and human complement component C5a (3). Recent reports have suggested that C5a mediates neutrophil attraction, aggregation, activation, and subsequent pulmonary endothelial damage (4-6). This sequence of events may be the primary pathogenetic mechanism for the

Address correspondence to Dr. Raffin, Assistant Chief of Medicine, Stanford University Medical Center, Stanford, CA 94305.

Received for publication 18 March 1985 and in revised form 19 February 1986.

1. Abbreviations used in this paper: ARDS, adult respiratory distress syndrome; CFU, colony forming units; EAP, endotoxin activated plasma; EVLW, extravascular lung water; MAP, mean arterial pressure; N/S, normal saline; PAP, pulmonary arterial pressure; PBSG, phosphatebuffered saline with $0.1 \%$ glucose; PCWP, pulmonary capillary wedge pressure; SVR, systemic vascular resistance.

J. Clin. Invest.

(c) The American Society for Clinical Investigation, Inc. $0021-9738 / 86 / 06 / 1812 / 05 \quad \$ 1.00$

Volume 77, June 1986, 1812-1816 development of ARDS in septic shock (3). In vitro studies have demonstrated that C5a generated from endotoxin or zymosanactivated plasma causes neutrophil aggregation (7). In addition, C5a-activated neutrophils are more adherent and are cytopathic to endothelial cells in tissue culture (8).

In vivo studies investigating mice which are genetically deficient in $\mathrm{C} 5$ have established that $\mathrm{C} 5$ is required for pulmonary edema formation in response to pneumococcal sepsis, scald wounds, and hyperoxia (9-11). When patients at high risk to develop ARDS were followed prospectively, detection of an elevated C5a was a useful predictor of the onset of ARDS (12). The present study was designed to evaluate the effects of a recently developed polyclonal antibody to C5a des arg on the development of ARDS in septic primates.

\section{Methods}

Anti-C5a des arg preparation. Immunogen was prepared from zymosanactivated human plasma and gel filtration/ion exchange chromatography according to the method described by Hugli and Chenoweth (13). The C5a des arg obtained was checked for its purity with cellulose acetate electrophoresis and amino acid analysis and used as the immunogen. New Zealand white rabbits were immunized with the immunogen, and antiserum to human complement $\mathrm{C} 5 \mathrm{a}$ des arg was obtained. Cross-reactivity is observed between anti-C5a and the parent $\mathrm{C} 5$ molecule but not with $\mathrm{C} 3 \mathrm{a}, \mathrm{C3}$, or $\mathrm{C4a}$. Therefore, anti-C5a des arg antibody is highly specific for C5a $(13,14)$.

Rabbit anti-human C5a des arg was titrated by radioimmunoassay (Upjohn Diagnostics, The Upjohn Company, Kalamazoo, MI). The titer of the antiserum (percent bound label/total label) used in this experiment was $1: 1,200$.

Immunoglobulin was prepared from $10 \mathrm{ml}$ of the antiserum with a modified method for horse IgG preparation (15). The final solution of IgG fraction from the antiserum was made particle-free by centrifugation at $18,000 \mathrm{rpm}$ for $30 \mathrm{~min}$. Concentration of protein was determined with an ultraviolet absorption at $280 \mathrm{~nm}$ (energy wavelength $280 \mathrm{~nm}, 1$ $\mathrm{mg} / \mathrm{ml}=1.5$ ). Nonspecific immunoglobulin from nonimmunized New Zealand white rabbits was prepared as above and was used as sham antibody infusion for animals in groups I and II.

Leukocyte aggregation. Anticoagulated (10 $\mathrm{U}$ heparin/ml blood) venous blood from Macaca fascicularis primates was used and neutrophils were obtained using a modified method of Craddock et al. (6). Our modification utilized phosphate-buffered saline with $0.1 \%$ glucose (PBSG) rather than Hanks' balanced salt solution with albumin.

Plasma was prepared by incubating $0.4 \mathrm{ml}$ of plasma with $20 \mu \mathrm{l}$ of $2 \mathrm{mg} / \mathrm{ml}$ endotoxin (E. coli J96) at $37^{\circ} \mathrm{C}$ for $30 \mathrm{~min}$ and at $56^{\circ} \mathrm{C}$ for 30 $\mathrm{min}$. Plasma was rendered particulate-free by centrifuging at $5,000 \mathrm{~g}$ for $10 \mathrm{~min}$ after the incubation with endotoxin. Aggregation of neutrophils was determined by aggregometry of neutrophils $\left(5 \times 10^{6}\right.$ cells $/ \mathrm{ml}$ of PBSG) in an aggregometer (PAP 4, Bio/Data Corp., Willow Grove, PA). The stimuli for aggregation were: $(a)$ endotoxin activated plasma, $(b)$ endotoxin activated plasma incubated for $15 \mathrm{~min}$ with nonspecific rabbit IgG, and $(c)$ endotoxin activated plasma incubated for $15 \mathrm{~min}$ with antiC5a des arg IgG. Aggregation was induced by adding $20 \mu \mathrm{l}$ of each re- 
spective stimulus to $250 \mu \mathrm{l}$ of neutrophil suspension. All studies reported were performed in triplicate.

Animal preparation. 12 adult male Macaca fascicularis primates (cynomolgus) weighing 4.8-7.2 $\mathrm{kg}$ were used in the study (Table I). They were initially anesthetized with $20 \mathrm{mg} / \mathrm{kg}$ of methohexital and $5 \mathrm{mg} / \mathrm{kg}$ of succinylcholine and maintained with $5 \mathrm{mg} / \mathrm{kg}$ per $\mathrm{h}$ of pentobarbitol and $0.1 \mathrm{mg} / \mathrm{kg}$ per $\mathrm{h}$ of pancuronium (Harvard infuision pump), and placed supine on a heating pad. The animals were intubated and ventilated with room air (Model 121, Health Dyne, Marietta, GA) using a tidal volume of $15 \mathrm{ml} / \mathrm{kg}$ and a respiratory rate adjusted to maintain $\mathrm{a} \mathrm{PaCO}_{2}$ of $35 \pm 3 \mathrm{mmHg}$.

A 4F arterial line was inserted through a femoral artery into the abdominal aorta to measure arterial pressures and sample arterial blood gases. A 5F thermal dilution Swan-Ganz catheter was inserted through a femoral vein to the pulmonary artery in order to measure pulmonary arterial and wedge pressures and to monitor cardiac output (Model 9520A, Edwards Thermodilution Cardiac Output Computer and Catheters, Santa Ana, CA). Position of the catheters was confirmed by pressure recordings on a four-channel strip chart recorder (Model 81064A, Hewlett Packard Co., Palo Alto, CA). A central venous line was inserted through the opposite femoral vein for administration of antibody. Precordial electrocardiograph leads were placed for evaluation of heart rate and rhythm.

Preparation of bacteria. E. coli. $\mathrm{J} 96(04: \mathrm{K} 6: \mathrm{H}+)$, a human bacteremicpyelonephritic isolate, is hemolytic, colicin $\mathrm{V}$ positive, resistant to the bactericidal action of normal serum, and simultaneously mannose and $\alpha \mathrm{Gal} 1 \mathrm{~T} 4 \rightarrow \beta \mathrm{Gal}$ binding (16). Stock cultures were stored in Luria broth with $10 \%$ glycerol at $-70^{\circ} \mathrm{C}$. Stock cultures were innoculated onto trypticase soy agar (TSA) plates and incubated at $37^{\circ} \mathrm{C}$ for $18 \mathrm{~h}$. The 18-h TSA cultures were harvested into normal saline using sterile fiberfree dacron swabs. The number of colony forming units (CFU) per milliliter of normal saline was determined by construction of standard curves by comparing the optical density at $620 \mathrm{~nm}(1-\mathrm{cm}$ light path) to the number of CFU of serially diluted cultures by the agar pour technique. The J96 CFU standard curves were reproducible as determined by identical curves on three different occasions that were each performed in triplicate. The stock intravenous bacteria inoculum was $2.0 \times 10^{9}$ bacteria/ml of saline. This inoculum represented a point on the CFUoptical density standard curve that was on the straight portion of the curve and was randomly checked and confirmed by culture techniques on four different occasions in duplicate during the course of the experiment.

Experimental protocol. Animals were separated into three experimental groups. Group I $(n=4)$ were control animals to receive $5 \mathrm{mg}$ pooled IgG from nonimmunized rabbits (sham $\mathrm{IgG}$ ) and $5 \mathrm{ml} / \mathrm{kg}$ of sterile saline as a mock $E$. coli infusion. Group II $(n=4)$ were septic animals to receive $5 \mathrm{mg}$ sham rabbit $\mathrm{IgG}$ and $5 \mathrm{ml} / \mathrm{kg}$ of the $E$. coli suspension $\left(1 \times 10^{10} / \mathrm{kg}\right)$. Group III $(n=4)$ were septic animals to receive $5 \mathrm{mg}$ of rabbit anti-human C5a des arg and $5 \mathrm{ml} / \mathrm{kg}$ of the $E$. coli suspension.

After the completion of line placement a pulmonary capillary wedge pressure (PCWP) was measured. If the PCWP was $<5 \mathrm{mmHg}$, fluid was administered according to a predetermined protocol to bring the PCWP to $5 \mathrm{mmHg}$. Throughout the experiment the fluid resuscitation protocol was used to maintain the PCWP at $5 \mathrm{mmHg}$.

The fluid resuscitation protocol consisted of normal saline (N/S) administered intravenously to maintain the PCWP at $5 \mathrm{mmHg}$. PCWP measurement was performed at a minimum interval of $0.2 \mathrm{~h}$. If the PCWP was $<5 \mathrm{mmHg}, 20 \mathrm{ml}$ of N/S was administered over $1 \mathrm{~min}$. A PCWP measurement was performed immediately after completion of the bolus. If the PCWP equaled $5 \mathrm{mmHg}$, no additional fluid was administered: If the PCWP was $<5 \mathrm{mmHg}, 40 \mathrm{ml}$ of N/S was administered over $1 \mathrm{~min}$ and a PCWP measurement was performed. This sequence was repeated until the PCWP equaled $5 \mathrm{mmHg}$. The pulmonary artery diastolic pressure was evaluated during the infusion of $\mathrm{N} / \mathrm{S}$. If the pulmonary artery diastolic pressure had an increase $>3 \mathrm{mmHg}$, the fluid administration was stopped and a PCWP measurement was performed. If the PCWP was $<5 \mathrm{mmHg}$, the fluid bolus was completed; if the PCWP equaled $5 \mathrm{mmHg}$, no additional fluid was administered.

Baseline data was obtained when the PCWP was $5 \mathrm{mmHg}$. Data included heart rate; systolic, diastolic, and mean arterial pressure (MAP); systolic, diastolic, and mean pulmonary arterial pressure (PAP); pulmonary capillary wedge pressure (PCWP); central venous pressure; thermal dilution cardiac output; arterial blood gases; and circulating peripheral neutrophil number.

Immediately after baseline data was obtained, antibody infusion was initiated. $5 \mathrm{mg}$ of sham or anti-C5a antibody was diluted in $40 \mathrm{ml} \mathrm{N} / \mathrm{S}$ and one-third of the solution was infused as a bolus over $1 \mathrm{~min}$. The remaining antibody was infused over $20 \mathrm{~min}$ using a Harvard infusion pump (Fig. 1).

In groups II and III, E. coli infusion $\left(1 \times 10^{10} \mathrm{E}\right.$. coli $\left./ \mathrm{kg}\right)$ was initiated 5 min after the initiation of the bolus antibody infusion and continued at a constant rate for 30 min using a Harvard infusion pump (Fig. 1). The end of the $E$. coli infusion was designated time zero and the protocol was carried out for $4 \mathrm{~h}$. Animals that survived the $4 \mathrm{~h}$ protocol were killed at $4.2 \mathrm{~h}$.

Arterial blood samples were collected every hour anaerobically and $\mathrm{PO}_{2}, \mathrm{PCO}_{2}$, and $\mathrm{pH}$ were measured using a Corning blood gas analyzer (Model 178, Corning Medical, Corning Glass Works, Medfield, MA). The alveolar-to-arterial oxygen difference $\left(\mathrm{AaDO}_{2}\right)$ was calculated (as-

Table I. Effects of Anti-C5a Antibodies on Hemodynamics in Septic Primates

\begin{tabular}{|c|c|c|c|}
\hline & $\begin{array}{l}\text { Control } \\
\text { (Group I) }\end{array}$ & $\begin{array}{l}\text { Septic } \\
\text { (Group II) }\end{array}$ & $\begin{array}{l}\text { Septic + Anti-C5a Antibodies } \\
\text { (Group III) }\end{array}$ \\
\hline Weight & $5.7 \pm 0.8 \mathrm{~kg}^{*}$ & $5.9 \pm 1.0$ & $5.5 \pm 0.3$ \\
\hline Survival & $4 / 4$ & $1 / 4$ & $4 / 4$ \\
\hline $\begin{array}{l}\text { Peripheral circulating neutrop } \\
\left(\text { cells } / \mathrm{mm}^{3}\right)\end{array}$ & $13.0 \pm 2.7 \S$ & $1.5 \pm 0.9$ & $1.5 \pm 0.6$ \\
\hline MAP (mmHg) & $108 \pm 15 \S$ & $60 \pm 9$ & $64 \pm 8$ \\
\hline MAP at $105 \mathrm{~min}(\mathrm{mmHg})$ & $107 \pm 17^{\prime \prime}$ & $36 \pm 18^{\prime \prime}$ & $64 \pm 12^{\prime \prime}$ \\
\hline Heart rate (beats/min) & $170 \pm 13 \S$ & $200 \pm 7$ & $208 \pm 21$ \\
\hline PCWP (mmHg) & $3 \pm 1$ & $4 \pm 1$ & $3 \pm 2$ \\
\hline Cardiac output (liters/min) & $1.2 \pm 0.2$ & $1.5 \pm 0.5$ & $1.5 \pm 0.3$ \\
\hline SVR (dyne-s/cm5) & $7037 \pm 1624 \S$ & $3349 \pm 1203$ & $3370 \pm 848$ \\
\hline PAP mean at $0 \mathrm{~min}(\mathrm{mmHg})$ & $14 \pm 3$ & $19 \pm 4$ & $16 \pm 3$ \\
\hline
\end{tabular}

\footnotetext{
* Mean \pm SD. $¥$ All values are obtained at 60 min except where noted. $\S$ Values significantly different $(P<0.05)$ from groups II and III. " All values significantly different $(P<0.05)$ from each other.
} 


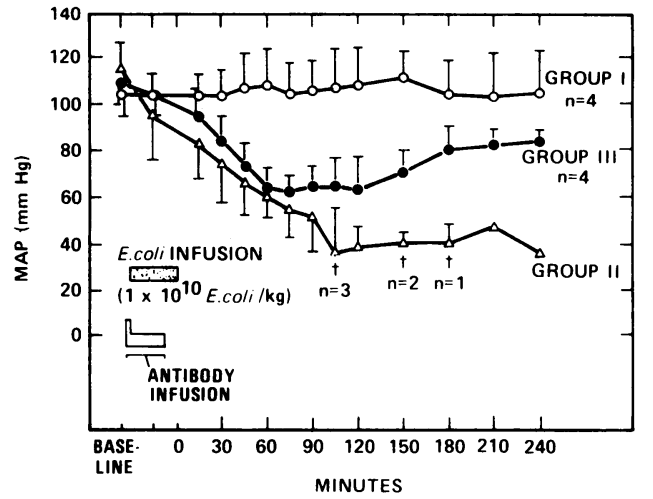

Figure 1. MAP throughout the experiment, survival, and timing of antibody and $E$. coli infusions are shown for group I control (no $E$. coli, sham IgG), group II ( $E$. coli, sham IgG), and group III ( $E$. coli, antiC5a IgG) animals. Three out of four septic primates in group II died (t, death). All septic primates treated with anti-C5a antibodies (group III) survived. Each group began with $n=4$ and the MAP of each group was significantly different from each other $(P<0.05)$ at 105 min. At 240 min there is no statistical difference between the MAP in groups I and III.

sumed respiratory exchange ratio of 0.8 ). Blood leukocyte counts were performed every $0.25 \mathrm{~h}$ from 0 to $1 \mathrm{~h}$ and then every $1 \mathrm{~h}$. Differential counts were done on Wright stained smears in duplicate. Peripheral circulating neutrophil number was obtained by multiplying absolute white blood cell count times the percent of segmented neutrophils plus the percent of banded neutrophils. Thermal dilution cardiac output measurements were performed every $0.25 \mathrm{~h}$ from 0 to $1 \mathrm{~h}$ and then every $1 \mathrm{~h} .3 \mathrm{ml}$ of normal saline cooled to $0^{\circ} \mathrm{C}$ was injected into the proximal port of the Swan-Ganz catheter and the mean of three consecutive cardiac output measurements initiated at end-exhalation was calculated.

Bacterial counts in blood. At $2.5 \mathrm{~h}$ a 2-ml blood sample was withdrawn from the femoral arterial line. Samples were obtained from two animals in group I, three animals from group II, and three animals from group III. The vial contained sterile heparin and was immediately processed to determine the number of CFU in the blood. An aliquot was lysed in sterile water and calibrated loops were used to inoculate MacConkey, blood, and trypticase soy agar plates. The plates were incubated at $37^{\circ} \mathrm{C}$ overnight and read the next day for growth. Positive cultures were gramstained, assessed for hemolysin, and assessed for slide agglutination using anti-J96 $\mathrm{O}$ antigen serum, as described elsewhere (17). Normal rabbit anti-sera was used as a negative control in the slide agglutination assay.

Gravimetric analysis. At the completion of the 4-h experimental protocol (or at death) $10,000 \mathrm{U}$ of sodium heparin was injected into a central venous line. After $5 \mathrm{~min}, 250 \mathrm{meq}$ of potassium chloride was injected intravenously and the endotracheal tube was clamped. At death a median sternotomy was performed. The lung hila were clamped and the lungs were excised. Gravimetric analysis was done using the method described in detail by Mihm et al. (18). Extravascular lung water (EVLW) was calculated and reported as milliliters per kilogram body weight.

Statistics. Comparisons were made between groups using the nonparametric Wilcoxon-signed rank test (19). $P<0.05$ was considered significant. All values in tables, figures, or text are mean values $\pm 1 \mathrm{SD}$.

\section{Results}

Leukocyte aggregation. Endotoxin activated plasma (EAP) alone or EAP plus nonspecific rabbit IgG served as a potent stimulus for leukocyte aggregation. When EAP was incubated with antiC5a antibody, the leukocyte aggregating potential of the stimulus was abolished.
Primate survival and hemodynamic data. The intravenous infusion of $1 \times 10^{10} \mathrm{E}$. coli $/ \mathrm{kg}$ proved to be lethal in three of four animals in group II (Fig. 1). Group II animals died at 105, 150 , and $180 \mathrm{~min}$ from cardiac arrhythmias and cardiovascular collapse (Fig. 1). The animals that died at 150 and $180 \mathrm{~min}$ also had florid pulmonary edema seen in the endotracheal tube. The fourth animal in group II survived the experimental protocol and had a MAP of $35 \mathrm{mmHg}$ at $4 \mathrm{~h}$ (Table I). In contrast, all control animals (group I) and all animals treated with anti-C5a antibodies (group III) survived for $4 \mathrm{~h}$ and were then killed.

All primates receiving $E$. coli developed septic shock manifested by hypotension, tachycardia, and decreased systemic vascular resistance (SVR) (Table I, Fig. I). All group III primates survived and had a significant recovery in their MAP beginning at $105 \mathrm{~min}(P<0.05)$. There was no significant difference between groups I, II, and III in mean PAP, PCWP, or cardiac output.

Septic primates in group II had significantly greater net fluid intake, $52 \pm 17 \mathrm{ml} / \mathrm{kg}$ per $\mathrm{h}$, than group I, $9 \pm 8 \mathrm{ml} / \mathrm{kg}$ per $\mathrm{h}$, or group III, $23 \pm 11 \mathrm{ml} / \mathrm{kg}$ per $\mathrm{h}$. There was no significant difference in net fluid intake between groups I and III.

Pulmonary injury. Pulmonary injury was assessed by analyzing $\mathrm{AaDO}_{2}$ and EVLW. Baseline $\mathrm{AaDO}_{2}$ results were not significantly different between groups I, II, and III (Fig. $2 A$ ). $\mathrm{AaDO}_{2}$ results calculated near death from arterial blood gases were significantly increased in group II animals, $65 \pm 29 \mathrm{mmHg}$ $(P<0.05)$ as compared with control (group I) primates, $23 \pm 6.5$
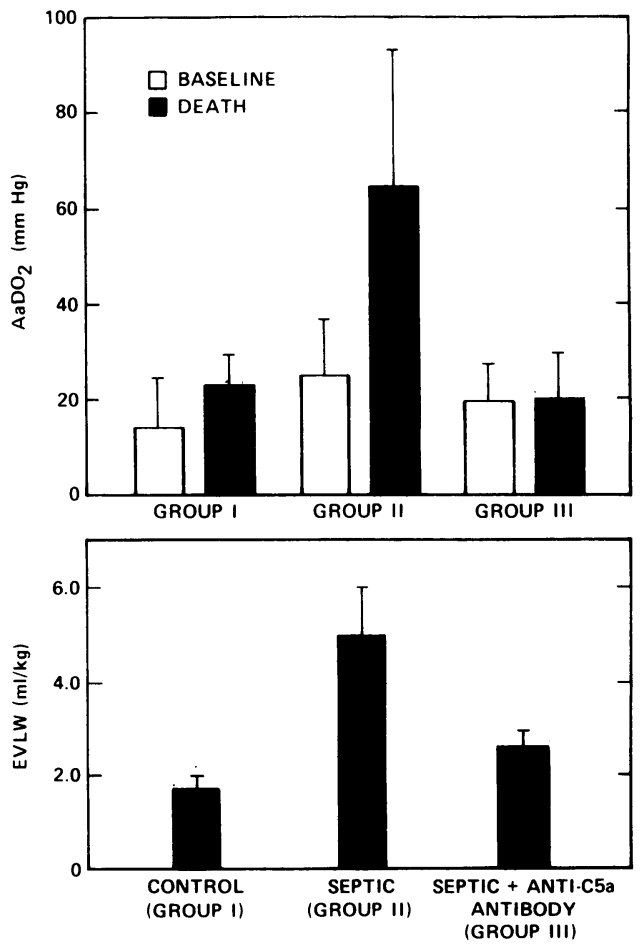

Figure $2 . \mathrm{AaDO}_{2}(A)$ was not significantly different at baseline between groups I, II, and III $(n=4)$. At death, septic primates (group II) had a significantly increased $\mathrm{AaDO}_{2}(P<0.05)$ compared to control (group I) or anti-C5a antibody treated septic primates (group III). EVLW $(B)$ determined by gravimetric analysis revealed that group II primates had a significantly increased EVLW $(P<0.05)$ compared to groups I or III primates $(n=4)$. 
$\mathrm{mmHg}$, or anti-C5a antibody (group III) treated primates, $20 \pm 10$ $\mathrm{mmHg}$ (Fig. 2).

EVLW results demonstrated significantly increased lung water $(P<0.05)$ in the septic primates (group II), $5.0 \pm 1.1 \mathrm{ml} /$ $\mathrm{kg}$, as compared with controls, $1.7 \pm 0.3 \mathrm{ml} / \mathrm{kg}$, or anti-C5a antibody treated primates, $2.6 \pm 0.4 \mathrm{ml} / \mathrm{kg}$ (Fig. $2 B$ ). There was no significant difference in EVLW between groups I and III (Fig. $2 B)$.

Peripheral circulating neutrophils. Peripheral neutrophil counts revealed a significant $(P<0.05)$ and sustained neutropenia in group II and III animals when compared to group I (Table I). There was no difference in circulating peripheral neutrophil counts between animals in groups II and III. Neutrophil counts before infusion of anti-C5a antibody or $E$. coli were 13.6 $\times 10^{3} / \mathrm{mm}^{3} \pm 4.1$ (group I), $11.6 \times 10^{3} / \mathrm{mm}^{3} \pm 5.2$ (group II), and $12.2 \times 10^{3} / \mathrm{mm}^{3} \pm 7.0$ (group III). The sustained neutropenia identified in Table I occurred 15 min before the end of the $E$. coli infusion, which is noted as time zero. The extent of neutropenia was equal in the septic group (group II) and the septictreated group (group III). $60 \mathrm{~min}$ after the end of the $E$. coli infusion there continued to be no significant difference between group II and group III primates. The neutrophil counts were as follows: $10.9 \times 10^{3} / \mathrm{mm}^{3} \pm 2.5$ (control), $2.4 \times 10^{3} / \mathrm{mm}^{3} \pm 2.1$ (septic), and $2.7 \times 10^{3} / \mathrm{mm}^{3} \pm 1.1$ (septic-treated).

Bacterial counts in blood. Bacterial counts were obtained in most but not all animals at $2.5 \mathrm{~h}$. Two septic control animals expired before $2.5 \mathrm{~h}$. Bacterial growth was not detected on any of the plates incubated with samples obtained from group I or control primates $(n=3)$. In contrast, group II or septic-control primates at $2.5 \mathrm{~h}$ had an average bacterial count of $3.9 \times 10^{4}$ $\mathrm{CFU} / \mathrm{ml}$ of blood $\pm 0.4(\mathrm{SD})(n=2)$. Group III or septic-treated primates at $2.5 \mathrm{~h}$ had an average bacterial count of $3.1 \times 10^{4}$ $\mathrm{CFU} / \mathrm{ml}$ of blood \pm 1.5 (SD) $(n=4)$. There was no difference between groups II and III. All cultures revealed gram-negative organisms that had uniform colony morphology on the plates, uniform and hemolytic colonies on blood agar, and uniform positive lactose fermenting colonies on MacConkey agar. Furthermore, the colonies were agglutinated only by anti-96 $\mathrm{O}$ antisera. From these data, it is evident that all monkeys administered intravenous $E$. coli $\mathrm{J} 96 \mathrm{had}$ a pure bacteremia due to this organism.

\section{Discussion}

This study was designed to determine if rabbit anti-human polyclonal C5a des arg IgG antibodies could prevent C5a-mediated leukocyte aggregation in vitro in primates and if so, could the anti-C5a antibody attenuate ARDS. Several investigators have demonstrated that $\mathrm{C} 5 \mathrm{a}$ is a critical component in the pathogenesis of ARDS (4-6). Specifically, respiratory failure in sepsis is considered to be a consequence of C5a-mediated leukocyte attraction, aggregation, activation, and subsequent pulmonary endothelial damage (3). Therefore, if anti-C5a antibody can functionally block the leukocyte-activating effects of C5a, it is possible that the pulmonary response of primates to live $E$. coli could be altered.

The results of the present study suggest that anti-C5a antibodies significantly attenuate C5a-mediated leukocyte aggregation in vitro and the respiratory and hemodynamic effects of sepsis in the primate Macaca fascicularis. The septic model produced in this study was acute and severe. The septic animals in group II had ARDS, as indicated by a significant increase in $\mathrm{AaDO}_{2}$ and $\mathrm{EVLW}$ (Fig. 2). Of interest is the high early mortality in group II animals. These observations demonstrate that the infusion of $1 \times 10^{10} \mathrm{E}$. coli/ $\mathrm{kg}$ is a considerable pulmonary and cardiovascular insult. This infusion of $E$. coli maintained a marked level of bacteremia that was not different in groups II or III. This demonstrates that anti-C5a did not decrease the degree of bacteremia.

Treatment with anti-C5a antibodies provided significant attenuation of the acute effects of sepsis in group III primates. Survival, pulmonary gas exchange, EVLW, and MAP were all significantly better in these animals. Animals treated with antiC5a antibodies also required significantly less fluid resuscitation to maintain similar PCWP pressures than septic animals in group II. The explanation for this finding could be twofold: first, the antibody therapy decreased capillary leak in the pulmonary and systemic vascular beds, and/or, second, improved pulmonary function minimized the added injury of hypoxemia to the cardiovascular insult. It is important to emphasize that fluid was administered only in response to a PCWP $<5 \mathrm{mmHg}$ in all experimental groups adhering to a strict protocol. In order to maintain adequate intravascular volume, fluid resuscitation requirements differed from group to group. The septic primates without anti-C5a antibodies had the largest fluid requirement $(52 \pm 17 \mathrm{ml} / \mathrm{kg} \mathrm{per} \mathrm{h})$ and this increase in fluid in all likelihood contributed to pulmonary edema, hypoxemia, respiratory failure, and death. Thus, it appeared that capillary leak was greatest in the septic primates (group II).

Treatment with anti-C5a antibodies did not prevent a severe and sustained leukopenia that occurred in all the bacteremic animals. This result raises questions regarding the role of neutrophil migration and margination in septic respiratory failure. It seems probable that the sustained neutropenia in group III animals is a consequence of neutrophils marginating either completely systemically or possibly in the lungs without causing as much injury.

The choice of the most appropriate antibody control in this study was difficult. We decided upon pooled rabbit IgG instead of using an antibody against a specific plasma protein even though it has been reported that nonspecific antigen-antibody complexes render neutrophils less responsive, as demonstrated by in vitro phagocytosis assays (20). However, the possibility still exists that anti-C5a antibody-antigen complexes might have had a nonspecific deleterious effect on neutrophil function, thereby lessening neutrophil-mediated injury.

In our model we believe this possibility is quite unlikely for several reasons. First, anti-C5a antibody was less than $10 \%$ of the total IgG infused. Thus, the overwhelming majority of the treatment IgG antibody was rabbit IgG similar to the pooled IgG infused in the septic controls. Second, only one-quarter of the total antibody was infused just 5 min before the bacterial infusion was begun. This short time span made it highly unlikely that neutrophils would be less responsive when the bacterial infusion was begun. The remainder of the antibody was infused while the bacterial infusion was being administered. Third, it is important to point out that circulating C5a levels are quite low before the initiation of sepsis; thus, antigen-antibody complex levels should have been low. And fourth, at the conclusion of the bacterial infusion and shortly thereafter, both MAP and peripheral neutrophil count began to fall equally in both the septiccontrol (group II) and septic-treated (group III) primates.

In summary, this study utilizing a severe sepsis model over 
$4 \mathrm{~h}$ demonstrates that treatment with rabbit anti-human C5a des arg antibodies attenuates ARDS and sepsis in Macaca fascicularis primates. Anti-C5a antibodies also block C5a mediated leukocyte aggregation in vitro. Three out of four septic animals not treated with anti-C5a antibodies died and all had decreased oxygenation, severe pulmonary edema, and profound hypotension. Septic primates treated with anti-C5a antibodies did not die, did not develop decreased oxygenation or significantly increased EVLW, and had a clear recovery in their MAP. These data suggest that $\mathrm{C} 5 \mathrm{a}$ is an important mediator in respiratory failure and septic shock due to bacteremia in primates.

\section{Acknowledgments}

We would like to thank Mitch Caldwell and Gail Benson and the Stanford Hospital Arterial Blood Gas Laboratory for their outstanding technical assistance. Kathy Weeks Stephens provided invaluable secretarial support.

This study was supported by The Levi Strauss Foundation and the David and Florence Ho Fund.

\section{References}

1. Fowler, A. A., R. F. Hamman, J. T. Good, K. N. Benson, M. Baird, D. J. Eberle, T. L. Petty, and T. M. Hyers. 1983. Adult respiratory distress syndrome: risk with common predispositions. Ann. Int. Med. 98:593-597.

2. Fein, A. M., M. Lippman, H. Holtzman, A. Eliraz, and S. K. Goldberg. 1983. The risk factors, incidence, and prognosis of ARDS following septicemia. Chest. 83:40-42.

3. Stevens, J. H., and T. A. Raffin. 1984. Adult respiratory distress syndrome. I. Etiology and mechanisms. Postgrad. Med. J. 60:505-513.

4. Tate, R. M., and J. E. Repine. 1983. Neutrophils and the adult respiratory distress syndrome: state of the art. Am. Rev. Respir. Dis. 128: 802-806.

5. Sacks, T., C. F. Moldow, P. R. Craddock, T. K. Bowers, and H. S. Jacobs. 1978. Oxygen radicals mediate endothelial cell damage by complement-stimulated granulocytes. An in vitro model of immune vascular damage. J. Clin. Invest. 61:1161-1167.

6. Craddock, P. R., A. Hammerschmidt, J. G. White, A. P. Dalmasso, and H. S. Jacob. 1977. Complement (C5a)-induced granulocyte aggregation in vitro: a possible mechanism of complement-induced leukostasis and leukopenia. J. Clin. Invest. 60:260-264.

7. Hammerschmidt, D. E., T. K. Bowers, C. J. Lammi-Keefe, H. S. Jacob, and P. R. Craddock. 1980. Granulocyte aggregometry: a sensitive technique for the detection of $\mathrm{C} 5 \mathrm{a}$ and complement activation. Blood. 55:898-902.

8. Tonnesen, M. G., L. A. Smedly, and P. M. Henson. 1984. Neutrophil-endothelial cell interactions: modulation of neutrophil adhesiveness induced by complement fragments C5a and C5a des arg and formylmethionyl-leucyl-phenylalanine in vitro. J. Clin. Invest. 74:1581-1592.

9. Hosea, S. F., E. Brown, C. Hammer, and M. Frank. 1980. Role of complement activation in a model of adult respiratory distress syndrome. J. Clin. Invest. 66:375-382.

10. Gelfand, J. A., M. Donelan, A. Hawiger, and J. F. Burke. 1982. Alternative complement pathway activation increases mortality in a model of burn injury in mice. J. Clin. Invest. 70:1170-1176.

11. Parrish, D. A., B. C. Mitchell, P. M. Henson, and G. L. Larsen. 1984. Pulmonary response of fifth component of complement-sufficient and -deficient mice to hyperoxia. J. Clin. Invest. 74:956-965.

12. Hammerschmidt, D. E., L. J. Weaver, L. D. Hudson, P. R. Craddock, and H. S. Jacob. 1980. Association of complement activation and elevated plasma C5a with adult respiratory distress syndrome: pathophysiological relevance and possible prognostic value. Lancet. i:947949.

13. Hugli, T. E., and D. E. Chenoweth. 1980 . Biologically active peptides of complement: techniques and significance of C3a and C5a measurements. In Laboratory and Research Methods in Biology and Medicine. R. M. Nakamura, W. R. Ditto, and E. S. Tucker, III, editors. Alan R. Liss, Inc., New York. 443-460.

14. Hugli, T. E., C. Gerard, M. Kawahara, M. E. Scheetz, II, R. Barton, S. Briggs, G. Koppel, and S. Russell. 1981. Isolation of three separate anaphylatoxins from complement-activated human serum. $\mathrm{Mol}$. Cell. Biochem. 41:59-66.

15. Wechter, W. J., J. W. Nelson, R. J. Perper, A. J. Parcells, K. W. Riebe, J. S. Evans, P. S. Satoh, and H. Ko. 1979. Manufacture of antithymocyte globulin (ATGAM) for clinical trials. Transplantation (Baltimore). 28:303-307.

16. Hull, R., R. Gill, P. Hsu, B. Minshow, and S. Falkow. 1981. Construction and expression of recombinant plasmids encoding Type 1 or D-Mannose-Resistant pili from a urinary tract infection. Escherichia Coli isolate. Infect Immun. 33:933-938.

17. O'Hanley, P., D. Lark, S. Falkow, and G. Schoolnik. 1985. Molecular basis of Escherichia coli colonization of the upper tract in Balb/ C mice. J. Clin. Invest. 75:347-360.

18. Mihm, F. G., T. W. Feeley, M. W. Rosenthal, and F. Lewis. 1982. Measurement of extravascular lung water in dogs using the thermalgreen dye dilution method. Anesthesiology. 57:116-122.

19. Snedecor, G. W., and W. G. Cochran. 1980. Statistical methods. 7th ed. Iowa State University Press, Ames, IA. 144-146.

20. Starkebaum, G., R. A. H. Jimenez, and W. P. Arend. 1982. Effect of immune complexes in human neutrophil phagocytic function. J. Immunol. 128:141-147. 